\title{
Publish and be read? A review of the usage of Loughborough University Library publications
}

Ruth Stubbings, Paul Reynolds, and Frank Parry

\section{The Authors}

Ruth Stubbings is an Academic Services Manager (Social Sciences and Humanities), Paul Reynolds the Service Development Manager, and Frank Parry an Academic Librarian (Science) all at Loughborough University Library.

\section{Acknowledgements}

The authors would like to acknowledge the hard work of the other members of the Publications group (Christine Hallam, Melissa Mattock and Dawn Cole) and the Information Skills Training Group (Elizabeth Gadd, Kelly Friend, Sheila Smith and Stephanie McKeating) in designing and analysing the publication questionnaire. We would also like to thank Inese Smith and the students of the Department of Information Science for their work in relation to the Self-guided tour.

\begin{abstract}
In 2000 Loughborough University Library reviewed its publications and redesigned their look, feel and content. The following year the Library asked its customers for feedback on the new publications and its web pages. This article describes the development of the library publications, the survey of customer attitudes and outlines future plans.
\end{abstract}

\section{Introduction}

In 1996 Loughborough University introduced a corporate style for all University publications including brochures, leaflets, posters and stationery. In response to this, the Library reviewed its own publications and developed a series of twelve leaflets. These aimed to describe Library services to the borrowers. Topics covered included borrowing from the Library, electronic information, photocopying, copyright and the Library regulations, see Figure 1 for a complete list. The Library also had a Self-guided tour leaflet that stood outside the series, that was updated every year.

The leaflets were of A5 size with cardboard covers in the corporate style of the University (shades of pink and purple!). The leaflets were numbered with the numbers being more prominent on the front cover than the actual title of the leaflet. Inside, the text was of a small font (size 10) in black print and there were no graphics or images. The leaflets were formal in tone and were designed to give the borrowers quite a lot of information on a single theme.

Despite the leaflets being useful, the Library had received several comments about them being unattractive to look at and too text based. At the same time the University had begun to relax its rules on corporate style, so it was felt that this would be a good time to review the publications again.

\begin{tabular}{|l|l|}
\hline Leaflet title & Leaflet number \\
\hline Library regulations & Library leaflet 1 \\
\hline
\end{tabular}




\begin{tabular}{|l|l|}
\hline Borrowing from the Library & Library leaflet 2 \\
\hline The Library catalogue - OPAC & Library leaflet 3 \\
\hline Services to part-time students & Library leaflet 4 \\
\hline Electronic information sources & Library leaflet 5 \\
\hline European Union publications & Library leaflet 6 \\
\hline British government publications & Library leaflet 7 \\
\hline Inter-Library loans & Library leaflet 8 \\
\hline The University Archives & Library leaflet 9 \\
\hline Photocopying and copyright & Library leaflet 10 \\
\hline Recommending books and serials & Library leaflet 11 \\
\hline Services to external users & Library leaflet 12 \\
\hline
\end{tabular}

Figure 1 - Library leaflets 1996

\section{Re-designing the guides}

In the spring of 2000, the University Library's Publications Group began to redesign the leaflets. The first thing the group did was to consider who the audience might be (Jackson 1984) and therefore the role of the leaflets. The group agreed that although all Library users would be a potential audience, the University has far more undergraduate students than postgraduate students or staff. Therefore, the majority of people who might use the leaflets would be undergraduate students and most probably first years. Considering this, the group felt that the content of the existing leaflets was probably too detailed and formal for the needs of a first year student. It was also considered unlikely that the design of these leaflets would attract such an audience.

It was agreed that the new library leaflets should:

- not be comprehensive, but should be a "taster" of what is available and be a quick reference tool

- be less formal and more user-friendly (Mayes 1979)

- avoid unnecessary or obscure jargon (Peterson, L. and Coniglio, J. W. 1987)

- concentrate on how to use library facilities rather than format of material

- complement the Library web pages (similar look and feel) and not duplicate information on them

- be written from the user's perspective!

- contain colour and images reflecting the library, especially the study environment, electronic and print information.

It was agreed that the leaflet series should be reduced to five leaflets in addition to the SelfGuided Tour leaflet. These were: Library uncovered - a general guide to the Library, the Library catalogue - OPAC, Part-time and distance learning, External readers and visitors and European Documentation Centre. Five leaflets were proposed as the group recognised that some library users required different information to first year students and that their information needs would have to be supported as well. In fact, we wanted the general leaflet to be short, welcoming, with clear information about particular services. The leaflet for parttime and distance learners would be more focused and provide more specific data on particular services. URLs would be provided at appropriate points in all the leaflets for those who wanted to have more detailed information on specific topics (Robinson 2000).

Information from the original leaflets that was not included in the guides was reconfigured 
and placed on other Library web pages, especially data on collection development, how to order material and the Library regulations.

The Library uncovered - a general guide to the Library was divided into five main areas: how to join the library, how to borrow books, what you will find in the library, IT and photocopying services and where to find help. The Library catalogue - OPAC guide was not written immediately, as the group knew that the Library was tendering for a new system. However it was planned for the leaflet to contain examples of searches rather than just descriptions of the functions. The External readers and visitors guide concentrated on who could become a member of the library with details of the joining process, as well as what services we offer to external readers. The Part-time and distance learning concentrated on services unique to part-time and distance learning students, including the nitty gritty of how to use particular facilities. The European Documentation Centre leaflet outlines what a European Documentation Centre is and how to gain help. The guides complement each other and students are encouraged to use them together.

We worked closely with the Audio-visual Services Department within the University to design the appearance of the leaflets. We required the leaflets to create a unique identity for the Library (Bryon, J. F. W. 1978), while following the corporate image of the University. We also wanted the leaflets to look part of a series but have their own identity. It was agreed to keep the general guide A5 size with approximately eight pages, but the others became DL (A4 folded three times). Due to cost, we only used full colour on the front cover of the Library uncovered. Two colours were used for the inside of all the leaflets and the front covers of the others. Several images of students, the library and electronic information were used on the front covers and in the inside of the general leaflet. Care was taken to ensure that text arrangement was adequately spaced and did not appear too densely packed. Information was arranged in small, clearly labelled segments. The Self-guided tour leaflet front cover was also changed so that it fitted into the new series. Each leaflet had its own colour, so that they were easily distinguishable.

It was agreed that the guides would only be given out in training sessions run for part-time or distance learning students. Full times students were shown the leaflets during Library induction and encouraged to collect them from the Library. The new guides proved popular, with over 4,000 copies of the Library uncovered - a general guide to the Library - being distributed in the first semester. A similar amount of copies of the Self-guided tour were utilised and a 1,000 Part-time and distance learning had been used by the middle of the second semester.

\section{Review of the new guides}

General comments from readers were positive in relation to the new guides. However, the Library felt that a formal survey would help the Publications group discover whether the aims of making the guides more user-friendly, simpler and attractive had worked. A two pronged approach was taken. Firstly, the Department of Information Science agreed to allow the Library to see the results of an assignment the post-graduate students undertake each year on the Self-guided tour. Secondly, a survey was drawn up by the Publications group and the Service Development Manager that would cover all of the Library publications and Library web pages. 
Review of the Self-guided tour by the Department of Information Science

The post-graduate students of the Department of Information Science reviewed the Selfguided tour. It was particularly pleasing that the Department was happy to provide the Library with detailed reviews undertaken by the students. Several suggestions, including better signs, physical appearance of the tour leaflet maps, instructions and route planning were incorporated into the following year's revisions.

\section{The survey}

The questionnaire aimed to discover whether the new guides were attractive, easy to locate and answered the readers' questions about the Library. The same questions were asked about all the publications, including the Self-guided tour. The following questions were asked about the printed publications: were they easy to find, were they easy to use, did they help the borrower to find the resources they required in the Library, did they answer most of their questions and were the publications attractive. Similar questions were asked about the library web pages including, is the Library web site easy to find from the University's home page, were the web pages easy to navigate, were they attractive and did they answer most of their questions. Graded responses were requested and the respondents were given the choice of disagree strongly, disagree, agree, agree strongly and not applicable (for those who had not used a particular publication). The questionnaires were disseminated both in print and via the web. In total 400 printed forms were distributed over a two week period in the Library. Library staff handed the questionnaires out at different times of the day directly to people as they entered the Library, explaining the aim of the survey. To encourage participation, a prize draw took place and three students were awarded book tokens. 177 print replies were received, a response rate of $44 \%$ and 185 online responses. Full time undergraduate and taught post-graduate students comprised the majority of respondents, $63 \%$ and $23 \%$ respectively. The balance was made up of staff $(12 \%)$, part-time students $(1 \%)$ and external users and visitors $(1 \%)$.

The results of the survey show that 213 (59\%) respondents had used the Self-guided tour and 198 ( $93 \%$ of those who had used it) found it easy to use. Similar proportions felt it answered their main questions about the service $(82 \%)$ and helped them to locate appropriate resources in the Library (87\%). The Self-guided tour is now a well-established publication and these figures indicate that it is also the Library's most well used guide. It also attracted many more free text comments than any other guide, some of which were critical of its layout and aspects of the number scheme used to identify resources. These seem to endorse the comments from the Department of Information Science students and were taken into consideration when the SGT was revised for the next academic year.

Only $65(18 \%)$ respondents claimed to have used the Library Uncovered. This figure is as disappointing as it is curious, given that a greater number (74) claimed that it had been easy to use! It is also clearly at variance with our estimate that approximately 4,000 of these guides were picked up from display stands over first semester. It was more pleasing that, of those who has used the Library Uncovered, 62 (95\%) agreed that it helped them to locate resources and answered their questions. Free text comments were generally positive but it is evident that more needed to be done to advertise this guide.

Only 11 respondents (3\%) had used the Part Time and Distance Learning Guide and an even smaller number $5(1.4 \%)$ the External readers and visitors guide. This usage rate is not surprising, as these leaflets are aimed at a small proportion of our users, but it was felt that 
sample sizes were too small to draw any general conclusions about the effectiveness of these publications.

No less than 318 (88\%) respondents said they had used the Library's web pages. This is a far larger percentage than for any of the printed leaflets (only $59 \%$ of respondents stated they had used the Self-guided tour, which was the most popular printed publication). The majority of respondents (77\%) felt that the web pages were easy to navigate and $82 \%$ felt they answered most of their questions, though 10 respondents did comment that they would like the pages to be more easily navigable. $76 \%$ thought the pages were visually attractive, a clear endorsement of work done to redesign the look of the pages the previous year. The survey did, however, raise some questions about the web pages. For instance, a significant minority (19\%) felt that the web pages were difficult to find from the University's home page and 11 respondents felt so strongly about this that they added free text comments regarding it including "make it easier to get to the Library web pages". It was also noted that the link from the University's home page should be to the Library's home page not to the Electronic Library page that contains information about e-journals and databases. Other free text comments suggested that the pages should be made more colourful or that different colours should be used to make them more readable. Some respondents suggested more images should be used and one in particular wanted "images of books and printed material". There were also remarks that there is too much text on the web pages and that links should be more prominent and not hidden in text. The Library is aware that the web pages do contain a great deal of content and will be reviewing these in the near future. We are in negotiations with the University to make the Library web pages more prominent on the University's home page.

\section{Future plans}

The results of the survey were incorporated into the summer 2001 revisions of our printed publications. We have also made the display of our publications more prominent in the Library and have succeeded in securing a link to the Library's web page directly from the University's home page. However, more work still needs to be done, including:

- Seeking ways of promoting printed publications more widely, outside the Library.

- Evaluating the External Readers and the Part Time and Distance Learning Leaflets.

- Lobbying for a more prominent link from the University home page to the Library pages.

- Reviewing the text content of the web pages.

- Reassessing the readability of the web pages in association with bodies such as the University's Disabilities and Additional Needs Service.

\section{Conclusion}

The results of the survey seem to show that those users who take and actually read our printed publications seem to appreciate both their design and content. However, it must be acknowledged that usage of the guides has been less than anticipated. These figures are not due to the guides being difficult to locate as display stands are situated throughout the Library and the results of the survey indicate $78 \%$ (282) of respondents agreed that the publications were easy to find. Rather, it would seem that there has been a substantial change in the way users seek help and advice about Library services. This change was evident in several of the free text comments. Our readers are now less likely to see printed publications as their main source of information and advice but are increasingly looking to our web pages. However, the survey shows that these publications clearly still add value for those users prepared to read them and do, for the time being at least, justify the significant amount of Library staff time spent creating, updating and promoting them. 


\section{Bibliography}

Bryon, J. W. F. (1978) The design of library publications. Art libraries journal. Vol. 3 (no. 2), pp.28-40.

Jackson, W. J. (1984) The user-friendly library guide. College and research libraries news. Vol. 45 (no. 9), pp.468 - 471.

Mayes, P. (1979) Checking the style by numbers. Library association record. Vol. 81 (no. 4), p. 177.

Peterson, L. and Coniglio, J. W. ( 1987) Readability of selected academic library guides. RQ. Vol. 27 (no. 2), pp. 233 - 239.

Robinson, K. (2000) Is it possible to communicate with first year students? SCONUL newsletter. Vol. 19 (Spring), pp. 25 - 26. 